\title{
Investigating the Influence of the Inlet Bypass Recirculation System on the Compressor Performance
}

\author{
S. $\mathrm{Li}^{1,2}, \mathrm{X}$. Yang ${ }^{1 \dagger}, \mathrm{W} . \mathrm{Li}^{1}$ and M. Tang ${ }^{1}$ \\ ${ }^{I}$ Liaoning Technical University, School of Mechanical Engineering, Fuxin, Liaoning Province, 123000, \\ China \\ ${ }^{2}$ Datong North Tianli supercharging Technology Co., Ltd. Datong, Shanxi Province, 037036, China
}

$\dagger$ Corresponding Author Email: yangxinle123000@hotmail.com

(Received September 9, 2020; accepted March 14, 2021)

\begin{abstract}
In the present study, an experimental method is proposed to study the influence of different slot widths, positions and structures of the compressor recirculation systems on the compressor performance. Obtained results indicate that the compressor flow range increases with the width of the recirculation slot at the expense of a narrower high-efficiency operating region. It is found that when the slot width is set to $3 \mathrm{~mm}$, the surge and choke margins are about $12 \%$ higher than that of the $2 \mathrm{~mm}$ slot. Moreover, it is found that when the position of the recirculation slot falls in the middle area of the guide wheel and far from the splitter blades, a larger surge margin can be achieved then it near the splitter blade. Adopting the recirculation structure without intake retaining ring structure can effectively broaden the compressor flow range. Compared with a straight slot intake structure, the compressor with an inclined slot intake structure has a greater surge margin in the high-speed region; however, the high-efficiency range of the latter scheme is smaller. Furthermore, the efficiency circle moves towards higher mass flow conditions. The present parametric study is expected to provide a guideline to design recirculation devices.
\end{abstract}

Keywords: Inlet bypass recirculation; Compressor performance; Compressor design.

\section{NOMENCLATURE}

$\begin{array}{ll}p_{t} & \text { dimensionless total pressure } \\ p_{s} & \text { dimensionless static pressure } \\ G_{C} & \text { actual airflow rate of compressor } \\ L_{i n} & \text { dimensionless length of the inlet pipe } \\ L_{e x} & \text { dimensionless length of the exhaust pipe } \\ G & \text { average flow in the pipeline } \\ \delta G & \text { flow disturbance in the pipeline } \\ n & \text { flow disturbance mode } \\ F_{C} & \text { compressor characteristics } \\ \Delta & \text { steady-state loss of the impeller. } \\ M & \text { flow inertia of the compressor } \\ \lambda & \text { flow inertia of the rotor } \\ \theta & \text { circumferential position } \\ \zeta & \text { time constant } \\ N & \text { turbocharger speed } \\ P_{C 1} & \text { compressor inlet total pressure } \\ P_{C 2} & \text { compressor outlet total pressure } \\ P_{T 1} & \text { turbine inlet total pressure } \\ P_{T 2} & \text { turbine outlet total pressure } \\ P_{0} & \text { ambient pressure }\end{array}$

$\begin{array}{ll}P_{1} & \text { lubricating oil inlet pressure } \\ T_{C 1} & \text { compressor inlet total temperature } \\ T_{C 2} & \text { compressor outlet total temperature } \\ T_{T 1} & \text { turbine inlet total temperature } \\ T_{T 2} & \text { turbine outlet total temperature } \\ T_{0} & \text { ambient temperature } \\ T_{1} & \text { lubricating oil inlet temperature } \\ T_{2} & \text { lubricating oil outlet temperature } \\ G_{c} & \text { actual flow rate of the compressor } \\ k & \text { specific heat ratio of the air, k=1.4 } \\ G_{m a x} & \text { choke flow of the compressor } \\ G_{\text {min }} & \text { surge flow of the compressor } \\ M_{1, \text { surge }} & \text { surge point flow rate of the } P_{1} \text { scheme } \\ M_{1, \text { choke }} & \text { choke point flow rate of the } P_{1} \text { scheme } \\ M_{2, \text { surge }} & \text { surge point flow rate of the } P_{2} \text { scheme } \\ M_{2, \text { choke }} & \text { choke point flow rate of the } P_{2} \text { scheme } \\ \sigma & \text { standard deviation } \\ x_{i} & \text { result of each test } \\ x & \text { average of multiple measurements } \\ s & \text { number of measurements }\end{array}$




\section{INTRODUCTION}

Studies show that in order to improve the power and economic indices of internal combustion engines, it should have a turbocharger. Moreover, it is essential to expand the operating flow range of the engine turbocharger. Further investigations revealed that installation of the turbocharger with an inlet recirculation system on a compressor, remarkably improves the pressure ratio and efficiency of the whole system. Yang et al. (2013) studied different techniques to expand the operating flow range of the compressor, and showed that intake bypass recirculation is the most effective technique in this regard.

In the past few years, many theoretical and experimental studies have been performed about the recirculation system. Accordingly, it is found that a properly designed compressor volute with a recirculation system can extend the stable operating range of the compressor so that a wider surge margin can be achieved accordingly. Fisher (1989) proposed the self-circulating structure and showed that the bypass recirculation structure can extend the stable operating range of the compressor. Moreover, Yang et al. (2010) studied the influence of inlet recirculation on the performance of a centrifugal compressor. They showed that with inlet recirculation, the inlet axial velocity is augmented, and the Mach number and flow angle significantly reduce. Meanwhile, obtained results revealed that the incidence angle reduces as the flow angle decreases, and the blade loading around the blade tip is affected by the inlet recirculation. Ramzi et al. (2013) simulated a slotted blade in a compressor cascade and found that it can reduce the secondary flow loss and the separation of the boundary layer at the corner. Furthermore, Mojaddam et al. (2014) studied the volute impact on the stable operating range of the compressor and accordingly, compared different methods for designing radial flow compressor volutes. Recently, He and Zheng (2019) found that at the inlet port of a low-speed impeller, an appropriate casing treatment device could eliminate stall, thereby resolving the rotating instability problem. Moreover, this device can effectively suppress the compression system surge at medium and high rotating speeds, thereby suppressing the mild and deep surges. Xiao et al. (2009) demonstrated that the casing treatment expands the stall margin with inclined blades in the cavity. They found that through the formation of a cavity with inclined blades at low mass flows, the reversed flow develops the counter swirl flow in front of the impeller inlet, which increases the pressure rise from the injection port to the bleed port, thereby improving the recirculation flow. Mirzabozorg et al. (2017) studied the effect of single shallow circumferential curves on the flow field and found that narrow curves have little effect on the efficiency, while wide curves cause a significant drop in the total pressure ratio and the efficiency of the compressor. Mao et al. (2018) showed that the optimal position of the slot to improve the stall margin and enhance the compressor efficiency near the stall condition locates near the blade leading edge. They studied the impact of the circumferential slots casing treatment over the rear rotor in a compressor with counter-rotating axial flow and found that the compressor with grooved casing treatment can enhance the flow stability. Meanwhile, they found that the compressor performance improves remarkably at near-stall conditions. Wang et al. (2019) demonstrated that compressor stability can be improved by different casing treatments, and flow management technology can improve efficiency. Nan et al. (2018) took two different transonic rotors with circumferential grooves, casing treatments and skewed slots to demonstrate that it can replace the high-speed compressor design with an equivalent-scale model. Zheng et al. (2013) proposed an asymmetric flow control method for the circulation system. Obtained results showed that compared with the conventional symmetrical flow control method, the surge flow of the compressor with the asymmetric self-circulation system reduces by about $10 \%$ so that a wider surge margin can be achieved. Harley et al. $(2014,2015)$ studied the development and growth rate of the recirculation flow in a centrifugal compressor of an automotive turbocharger. They established a mathematical correlation between the development rate of the recirculation area and the compressor stage and accordingly, simulated the performance of the centrifugal compressor with air recirculation. Tamaki et al. (2010, 2012, 2015) studied the influence of the intake air recirculation on the performance of the turbocharged centrifugal compressor. They found that the compressor's selfcirculation system draws off the blade tip airflow, reduces the flow choke, and moves the shock wave backward. Then they investigated the effect of expanding the working margin and found that installing the guide vanes in the circulation chamber can remove the pre-swirl, thereby reducing losses originating from the flow mixing with the mainstream. Yang et al. (2016a) investigated the unsteady effects of self-circulation on the flow in a transonic centrifugal compressor. They showed that the compressor volute with a self-circulation structure could restrain the flow deformation from downstream perturbations, thereby reducing the deformation amplitude of the inlet flow. Furthermore, Yang et al. (2016b) studied the recirculation characteristics of the double-suction centrifugal compressor with asymmetric intake structure and found that for different operating conditions, the recirculation velocity distribution of front and rear impellers along the circumferential direction are uneven. They also proved that the static pressure distribution at the front impeller can be utilized to determine the non-uniformity and distribution of the return velocity of the front impeller on the circumference. They found that the flow pattern in the rear impeller is affected by the inlet flow field distortion of the rear impeller, asymmetric distribution of the upstream slot circumference and the asymmetric structure of the volute.

Performed investigations indicate that the recirculation system can broaden the stable operating range of the compressor and provide a wider surge margin accordingly. In some investigations, the 
onset of the surge phenomenon was modeled. It is found that after enlarging the bypass recirculation tank of the compressor, such surge phenomenon disappears. However, there are still many questions about the influence of the geometry and the structure of the recirculation system on the compressor performance. In the present study, a series of experiments have been carried out to quantify the impact of different factors on the compressor performance, and find the optimum layout and parameters of the recirculation system. Concretely, the compressor characteristic curves for different widths, positions, and structural forms of recirculation tanks will be investigated.

\section{THE ESTABLISHMENT OF THE COMPRESSOR SYSTEM MODEL}

\subsection{Compressor system structure}

In order to model the compressor system, the simplified structure of the compressor system is initially defined according to its working environment. Figure 1 shows that the main components of the compressor system include the intake pipe, the compressor and the exhaust pipe.

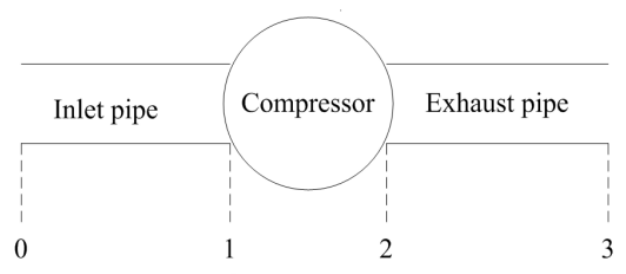

Fig. 1. Schematic configuration of the compressor system.

\subsection{Compressor system model}

In this section, the main components of the compressor system are analyzed through the component modeling method to construct a mathematical model of the compressor system based on the pressure balance, flow continuity, and momentum conservation laws.

(1) Modeling inlet and exhaust pipes

The velocity potential of the flow field of the inlet and exhaust pipes should satisfy the Laplace equation. Moreover, according to the Bernoulli equation, the pressure loss of the inlet and exhaust pipes can be calculated from Eqs. (1) and (2), respectively.

$$
\begin{aligned}
& p_{t 1}-p_{t 0}=-L_{i n} \cdot \frac{d G}{d t}-\frac{1}{n} \frac{\partial(\delta G)}{\partial t} \\
& p_{s 3}-p_{s 2}=-L_{e x} \cdot \frac{d G}{d t}-\frac{1}{n} \frac{\partial(\delta G)}{\partial t}
\end{aligned}
$$

In Eq. (1), the average flow rate and the flow rate disturbance are utilized to establish a pressure balance correlation, which reflects the conservation of the momentum in the flow field of the inlet pipe.

\section{(2) Compressor model}

Considering the pressure balance and viscosity loss of the compressor and the flow inertia in the impeller channel, the mathematical model of the compressor can be expressed in the form below:

$\left\{\begin{array}{l}p_{s 2}-p_{t 1}=F_{c}(G)-\mu \cdot \frac{d G}{d t}-\Delta-\lambda \frac{\partial(\delta G)}{\partial \theta}-\mu \frac{\partial(\delta G)}{\partial t} \\ \zeta\left(\frac{\partial \Delta}{\partial t}+\frac{\partial \Delta}{\partial \theta}\right)=\Delta_{s s}(G)-\Delta(G, t)\end{array}\right.$

\section{(3) Compressor system model}

Considering the pressure balance correlation of the compressor system, the pressure rise of the compressor can be mathematically expressed as:

$$
\begin{aligned}
& \psi=p_{\mathrm{s} 3}-p_{t 0}= \\
& \left(p_{t i}-p_{t 0}\right)+\left(p_{s 2}-p_{t 1}\right)+\left(p_{s 3}-p_{s 2}\right) \\
& =F_{\mathrm{c}}(G)-\Delta-\left[\begin{array}{l}
\left(L_{i n}+L_{e x}+\mu\right) \frac{d G}{d t}+ \\
\left(\frac{2}{n}+\mu\right) \frac{\partial(\delta G)}{\partial t}+\lambda \frac{\partial(\delta G)}{\partial \theta}
\end{array}\right]
\end{aligned}
$$

In summary, the whole compressor system can be mathematically modeled as follows:

$$
\left\{\begin{array}{l}
\left(L_{i n}+L_{e x}+\mu\right) \frac{d G}{d t}+\left(\frac{2}{n}+\mu\right) \frac{\partial(\delta G)}{\partial t}+ \\
\lambda \frac{\partial(\delta G)}{\partial \theta}=F_{\mathrm{c}}(G)-\Delta-\psi \\
\zeta\left(\frac{\partial \Delta}{\partial t}+\frac{\partial \Delta}{\partial \theta}\right)=\Delta_{s S}(G)-\Delta(G, t)
\end{array}\right.
$$

It is worth noting that in this model, the influence of the flow loss on the compressor performance is considered, and the dynamic correlation between the compressor pressure rise and the flow rate is described.

\section{ANALYZING THE WORKING MECHANISM OF COMPRESSOR INLET RECIRCULATION SYSTEM}

Figure 2 shows the working principle of the recirculation system of the compressor inlet. Figure 2(a) indicates that when the compressor flow reduces and approaches the surge condition, due to the high pressure at the intake recirculation system, part of the gas flows into the compressor inlet through the bypass channel and the circulation slot. Then the air flow at the inlet port of the compressor increases, thereby avoiding the separation of the airflow on the suction surface of the inlet of the compressor blade and moving the surge boundary to a small flow.

Moreover, Fig. 2(b) shows that when the compressor flow is close to the choke flow, due to the high pressure at the compressor inlet and the low pressure at the intake recirculation system, part of the gas in the compressor inlet is directly sucked into the rear section 
of the wind deflector through the bypass channel. Therefore, the formation of the flow with a high Mach number and blockage at the inlet of the wind deflector is avoided. Finally, the block boundary of the compressor moves towards the large flow.

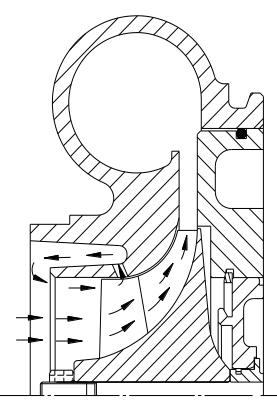

(a) The operation of inlet bypass recirculation system during surge

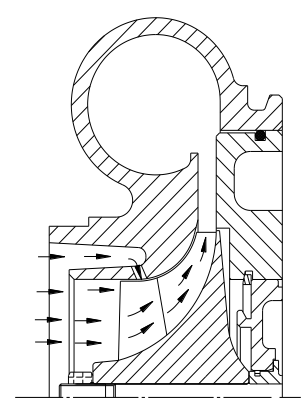

(b) The operation of inlet bypass recirculation system during choke
Fig. 2. Operation of the recirculation system

\section{EXPERIMENTAL DEVICES}

\subsection{Selection of the turbocharger}

The experiment is conducted by using the JP9523-76 turbocharger in a compressor with a bypass recirculation system. It should be indicated that the turbocharger is a forward-bending type and has backward-curved radial impellers with 7 main flow blades and 7 splitter blades.

Table 1 Main characteristics of the compressor.

\begin{tabular}{|c|c|c|}
\hline Title & Value & Unit \\
\hline Turbocharger model & JP9523-76 & - \\
\hline Impeller inlet diameter & 67.3 & $\mathrm{~mm}$ \\
\hline $\begin{array}{c}\text { Impeller outlet } \\
\text { diameter }\end{array}$ & 93 & $\mathrm{~mm}$ \\
\hline $\begin{array}{c}\text { Impeller blade outlet } \\
\text { width }\end{array}$ & 6.3 & $\mathrm{~mm}$ \\
\hline $\begin{array}{c}\text { Air flow angle of } \\
\text { impeller inlet hub }\end{array}$ & -69 & $\circ$ \\
\hline $\begin{array}{c}\text { Air flow angle of } \\
\text { impeller inlet shroud }\end{array}$ & -32 & $\circ$ \\
\hline $\begin{array}{c}\text { Back bend angle at } \\
\text { Impeller exit }\end{array}$ & -25 & $\circ$ \\
\hline $\begin{array}{c}\text { Diffuser width } \\
\text { 0-0 Cross section area } \\
\text { of compressor volute }\end{array}$ & 13.46 & $\mathrm{~cm}^{2}$ \\
\hline
\end{tabular}

Table 1 shows the main characteristics of the compressor. It is worth noting that a parallel wall vane-less diffuser is attached to the downstream of the impeller. Moreover, the intake bypass recirculation system consists of a circular slot structure and the inner wall of the volute is connected to the compressor volute through three axial stiffeners, which are uniformly distributed along the circumferential direction.

Figure 3 shows the recirculation structure of the compressor intake air. It is observed that the center of the circulation slot is located at $1 / 2$ of the axial position between the leading edges of the long and short blades of the compressor impeller, where the distance from the reference plane is marked as $L_{2}$. This point is considered as the center and then takes $1.2 \mathrm{~mm}$ on the left and right sides as the step length of the circulation slot position. Figure 3 shows that the locations of the corresponding points are controlled by $L_{1}$ and $L_{3}$. Based on the area ratio of the circulation airflow in the inlet and outlet, the widths of the circulation slots are determined as 2, 3 and 4 $\mathrm{mm}$. It is worth noting that $B$ denotes the width of the circulation slot. Moreover, $L_{1}, L_{2}$, and $L_{3}$ are the distances from the centerline of the circulation slot to the reference plane. Figure 4 shows the design scheme of the compressor intake air recirculation structure, in which $P 1, P 2$ and $P 3$ are the design schemes for different widths of the recirculation slot. Moreover, $P 2, P 4$, and $P 5$ are the design schemes for different positions of the recirculation slot, while $P 2$, $P 6, P 7$ and $P 8$ are the design schemes for variable recirculation system structures.

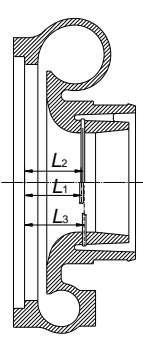

(a)

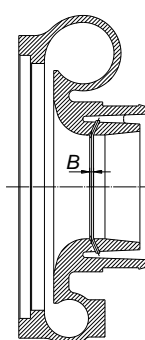

(b)

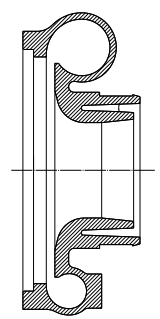

(c)

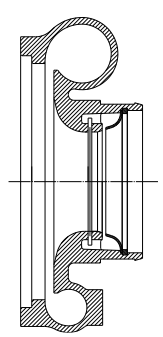

(d) (a) Straight slot structure

(b) 24 inclined slot structure

(c) Non-recirculation slot structure

(d) Straight slot structure with an intake collar

Fig. 3. Compressor intake air recirculation structure.

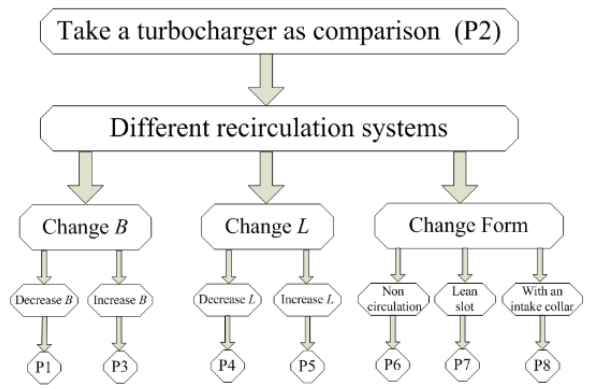

Fig. 4. Design scheme of the compressor air intake recirculation structure. 
S. Li et al. / JAFM, Vol. 14, No. 5, pp. 1295-1305, 2021.

Table 2 Design parameters of the compressor air intake recirculation structure.

\begin{tabular}{|c|c|c|l|}
\hline Scheme number & Slot location & Slot width/mm & \multicolumn{1}{|c|}{ Slot structure } \\
\hline$P 1$ & $L_{2}$ & 2 & Straight slot \\
\hline$P 2$ & $L_{2}$ & 3 & Straight slot \\
\hline$P 3$ & $L_{2}$ & 4 & Straight slot \\
\hline$P 4$ & $L_{1}$ & 3 & Straight slot \\
\hline$P 5$ & $L_{3}$ & 3 & Straight slot \\
\hline$P 6$ & None & None & Non-intake circulation \\
\hline$P 7$ & $L_{2}$ & 3 & $24^{\circ}$ inclined slot \\
\hline$P 8$ & $L_{2}$ & 3 & Straight slot with an intake collar \\
\hline
\end{tabular}
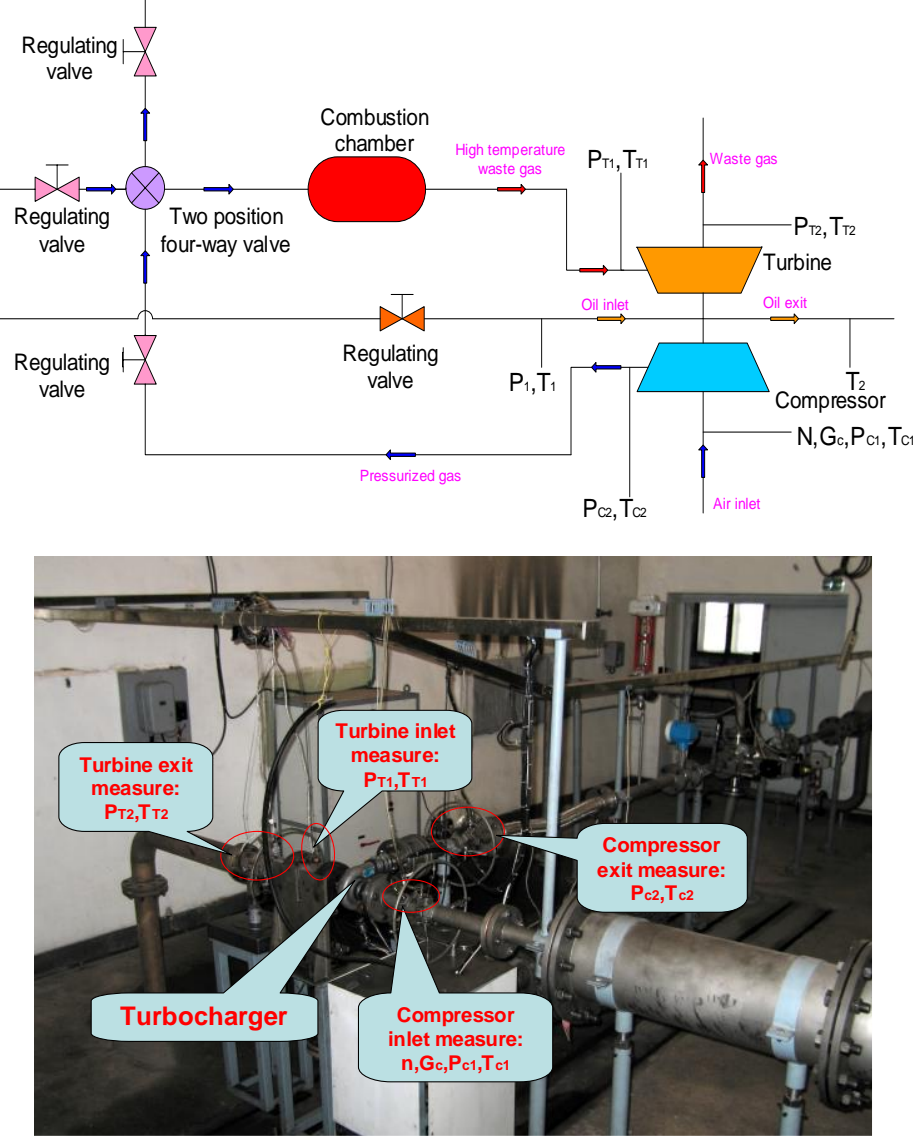

Fig. 5. Turbocharger test bench.

Table 2 presents the design parameters of the compressor air intake recirculation structure. Among various design schemes of the recirculation system structure, it is intended to investigate the influence of the location and width of the recirculation tank and the influence of the recirculation system structure on the compressor performance. Therefore, the influence of the recirculation system on the compressor performance is studied comprehensively.

\subsection{Experimental system and method}

In this section, an experiment is carried out to investigate the performance of the turbocharger. An external air source is utilized to supply the compressed air, which directly drives the turbine after being heated by the combustion chamber.
Figure 5 indicates that the test bench mainly consists of six parts, including the controllable air source, gas heater for the combustion chamber, oil lubricating system, monitoring system, control system and piping system. The compressed air initially enters the combustion chamber. Then, the fuel supply is adjusted to simulate the combustion and heating process of the engine and the turbine is promoted to operate. Then, the compressor is driven to compress the air, and the compressor characteristic test is performed.

\subsection{Experimental requirements}

In this experiment, diverse rotating speeds, including 50'000, 60'000, 70'000, 80'000, 90'000 and 100'000 rpm are considered. At each rotating speed, the test is performed from the choke flow to the surge flow 
and 5 10 points are measured at regular intervals. In all tests, the lubricant inlet temperature varies within the range of $50 \sim 75{ }^{\circ} \mathrm{C}$, while the returning oil temperature is less than $120{ }^{\circ} \mathrm{C}$. Moreover, the lubricating oil inlet pressure is set to $0.2 \sim 0.4 \mathrm{MPa}$, and the temperature before the turbine is less than $750{ }^{\circ} \mathrm{C}$. The inlet vacuum of the compressor and the outlet pressure of the turbine are less than $6 \times 10^{3} \mathrm{~Pa}$ (without air filter) and $5 \times 10^{3} \mathrm{~Pa}$ (without exhaust pipe).

\subsection{Instrumentation and measurement accuracy}

The turbocharger speed is measured by a magneticelectric tachometer with a measuring range of 20'000 200'000 rpm. Table 3 shows the Instrumentation and measuring accuracy.

Table 3 Instrumentation and Measuring Accuracy.

\begin{tabular}{|c|c|c|}
\hline Title & Sensors & $\begin{array}{c}\text { Measuring } \\
\text { accuracy }\end{array}$ \\
\hline $\begin{array}{c}\text { Turbocharger } \\
\text { speed }\end{array}$ & $\begin{array}{c}\text { magnetic-electric } \\
\text { tachometer }\end{array}$ & $\pm 0.2 \%$ \\
\hline $\begin{array}{l}\text { Turbocharger } \\
\text { flow rate }\end{array}$ & $\begin{array}{c}\text { double button } \\
\text { flow meter }\end{array}$ & $\pm 1.5 \%$ \\
\hline $\begin{array}{l}\text { Compressor } \\
\text { pressure }\end{array}$ & $\begin{array}{c}\text { U-tube } \\
\text { manometer }\end{array}$ & $0.5 \%$ \\
\hline $\begin{array}{c}\text { Turbine and } \\
\text { oil inlet } \\
\text { pressure }\end{array}$ & $\begin{array}{l}\text { spring-type } \\
\text { pressure gauge }\end{array}$ & $\geq 2.5$ grade \\
\hline $\begin{array}{l}\text { Compressor } \\
\text { inlet } \\
\text { temperature }\end{array}$ & $\begin{array}{l}\text { copper } \\
\text { constantan } \\
\text { thermocouple } \\
\text { thermometer }\end{array}$ & $\pm 0.2^{\circ} \mathrm{C}$ \\
\hline $\begin{array}{c}\text { Compressor } \\
\text { outlet } \\
\text { temperature }\end{array}$ & $\begin{array}{c}\text { platinum } \\
\text { resistance } \\
\text { thermometer }\end{array}$ & $\pm 0.1^{\circ} \mathrm{C}$ \\
\hline $\begin{array}{l}\text { Turbine } \\
\text { temperature }\end{array}$ & $\begin{array}{c}\text { Nickel- } \\
\text { chromium/nickel } \\
\text { - aluminum } \\
\text { thermocouple } \\
\text { thermometer }\end{array}$ & $\pm 1{ }^{\circ} \mathrm{C}$ \\
\hline $\begin{array}{c}\text { Oil } \\
\text { temperature }\end{array}$ & $\begin{array}{c}\text { thermal } \\
\text { resistance } \\
\text { thermometer }\end{array}$ & $2^{\circ} \mathrm{C}$ \\
\hline
\end{tabular}

\subsection{Measurement parameters and experimental error processing method}

During the experiment, it is of significant importance to monitor and analyze key parameters, including the ambient pressure and temperature, turbocharger speed, actual airflow rate of the compressor, compressor inlet total pressure and total temperature, compressor outlet total pressure and total temperature, turbine inlet total pressure and total temperature, turbine outlet total pressure and total temperature, lubricating oil inlet pressure and temperature and lubricating oil outlet temperature. It is worth noting that during the test, three samplings are performed for each measurement and then the average value is considered as the measured value.
In order to reduce measurement error caused by environmental factors, the parameters are converted into standard conditions. In other words, the corrected mass flow, total pressure ratio and isentropic efficiency of the compressor are used in the experiment. These parameters can be mathematically expressed as the following (Zhu 1992):

$$
\begin{aligned}
& G_{c o r}=G_{c} \times \frac{100}{P_{C 1}} \times \sqrt{\frac{T_{C 1}}{298}} \\
& \pi_{c}=\frac{P_{C 2}}{P_{C 1}} \\
& \eta_{C}=\frac{T_{C 1}\left(\pi_{C}^{(k-1) / k}-1\right)}{T_{C 2}-T_{C 1}}
\end{aligned}
$$

Uncertainty of the experimental data results is expressed as the following (Moffat 1988):

$\delta_{R}=\sqrt{\left(\frac{\partial R}{\partial x_{1}}\right)^{2} \delta x_{1}^{2}+\left(\frac{\partial R}{\partial x_{2}}\right)^{2} \delta x_{2}^{2}+\cdots+\left(\frac{\partial R}{\partial x_{i}}\right)^{2} \delta x_{i}^{2}+\cdots}$

Accordingly, uncertainty equations for the compressor flow and efficiency can be expressed in the form below:

$\delta_{G_{c}}=\sqrt{\left(\frac{\partial G_{c}}{\partial T_{C 1}}\right)^{2} \delta T_{C 1}^{2}+\left(\frac{\partial G_{c}}{\partial T_{C 2}}\right)^{2} \delta T_{C 2}^{2}+}$

$\delta_{\eta_{c}}=\sqrt{\left(\frac{\partial \eta_{c}}{\partial T_{C 1}}\right)^{2} \delta T_{C 1}^{2}+\left(\frac{\partial \eta_{c}}{\partial T_{C 2}}\right)^{2} \delta T_{C 2}^{2}+}$

Moreover, uncertainty equation for the compressor pressure ratio is:

$\delta_{\pi_{c}}=\sqrt{\left(\frac{\partial \pi_{c}}{\partial P_{C 1}}\right)^{2} \delta P_{C 1}^{2}+\left(\frac{\partial \pi_{c}}{\partial P_{C 2}}\right)^{2} \delta P_{C 2}^{2}}$

\section{RESULTS AND DISCUSSION}

In the present study, eight tests are carried out on the turbocharger test bench to investigate the compressor performance at different operating conditions. Then, the impact of the width, location and structure of the bypass recirculation slot on the compressor performance is investigated.

The compressor flow range is usually quantified by the flow ratio as the following:

$\frac{\Delta G}{G_{\mathrm{m}}}=\frac{G_{\max }-G_{\min }}{\left(G_{\max }+G_{\min }\right) / 2}$ 
For the performance curve of a compressor, it is not only necessary to focus on the flow range, pressure ratio and efficiency of the compressor, but also the position of the operating conditions in the performance curve and the margin of the performance curve should be considered. More specifically, the engine operating point should fall in the high-efficiency area of the compressor performance curve, and there should be a reasonable safety margin from the surge line and blocked area to ensure the normal operation of the engine. In order to compare the positional correlation of the performance curves of each program, two concepts of the surge line change and blockage change are defined, which are used to express the change and positional correlation of surge line and choke area between each scheme and the reference scheme.

Taking the $P 1$ scheme as an example, variation of the surge margin can be mathematically expressed as:

$\frac{M_{2, \text { surge }}-M_{1, \text { surge }}}{M_{1, \text { choke }}-M_{1, \text { surge }}} \times 100 \%$

The choke margin of the $P 1$ scheme can be mathematically expressed as:

$$
\frac{M_{1, \text { choke }}-M_{2, \text { choke }}}{M_{1, \text { choke }}-M_{1, \text { surge }}} \times 100 \%
$$

The associated standard deviation can be mathematically expressed as:

$$
\sigma=\sqrt{\frac{\sum\left(x_{i}-x\right)^{2}}{s-1}}
$$

\subsection{The influence of the compressor recirculation slot width on the machine performance}

Figures 6 and 7 show the effect of the recirculation slot width on the compressor performance. It is observed that the recirculation slots of $P 1, P 2$ and $P 3$ have straight slot structures at the $L_{2}$ position with widths of $2 \mathrm{~mm}, 3 \mathrm{~mm}$ and $4 \mathrm{~mm}$, respectively. Figure 6 indicates that the $P 1$ scheme has a narrower flow range, while $P 2$ and $P 3$ schemes obtain a wider flow range. The surge lines of $P 2$ and $P 3$ schemes are closer to each other, and they move to a small flow compared with the $P 1$ scheme. It is found that the $P 3$ scheme has a larger surge margin when the rotating speed is set to $100^{\prime} 000 \mathrm{rpm}$. When the rotating speed of the turbocharger exceeds $70^{\prime} 000$ rpm, the choke flow of the $P 2$ scheme is larger than that of the $P 3$ scheme, while the choke flow of the $P 1$ scheme is the smallest. This shows that as the circulation slot width increases, the bypass flow rate increases and an optimum value appears accordingly. Subsequently, the compressor flow range expands. When the bypass flow rate increases, the influence of the bypass intake air on the impeller main airflow increases too. Therefore, the area of the highefficiency circle decreases.

Figure 7 shows that the mass flow ratio, surge margin and choke margin of the compressor change as the width of the recirculation slot changes. It is observed that the flow range of the $P 1$ scheme is the narrowest. When the rotating speed of the turbocharger varies within the range of $80^{\prime} 000 \mathrm{rpm} \sim 90^{\prime} 000 \mathrm{rpm}$, the flow range of the $P 2$ scheme is larger than that of the $P 3$ scheme. The flow range of the $P 2$ scheme in the low-speed area and the limit speed area is smaller than that of the $P 3$ scheme. In order to make the engine perform efficiently, the turbocharger should operate in the high-efficiency area. It is found that the $P 2$ scheme has the widest flow range in the highefficiency area. Therefore, the $P 2$ scheme is selected as the best comparison scheme.

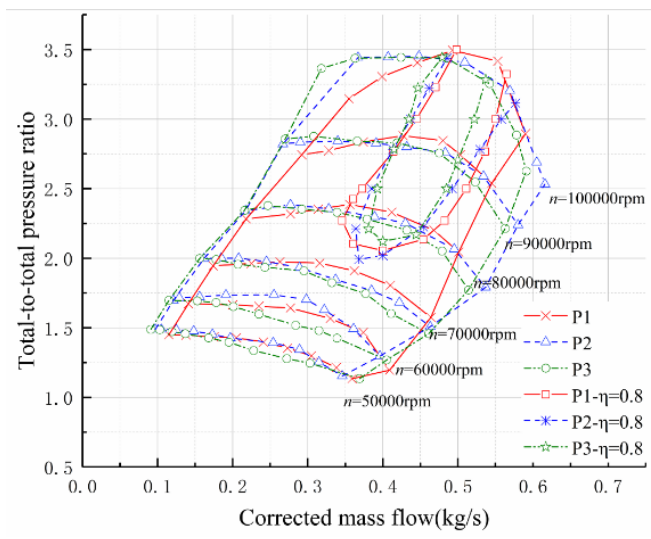

Fig. 6. Effect of the recirculation slot width on the compressor performance.

Figure 7 illustrates the positional correlation of several performance curves. It should be indicated that the $P 2$ scheme is considered as the comparison benchmark. Then, variations of the surge margin and choke margin under each speed line are analyzed accordingly. Taking the rotation speed of 50'000 rpm as an example, the value of the $P 1$ surge margin is negative, which indicates that the mass flow at the surge point of $P 1$ scheme is larger than that of the $P 2$ scheme. Moreover, the surge margin of the $P 1$ scheme is smaller than that of the $P 2$ scheme. Moreover, the value of the $P 1$ choke margin is positive. This indicates that the mass flow at the choke point of $P 1$ scheme is larger than that of the $P 2$ scheme. Accordingly, the choke margin of the $P 1$ scheme is larger than that of the $P 2$ scheme.

Figure 7 shows that the surge margin and choke margin of the $P 1$ scheme are about $12 \%$ lower than that of the $P 2$ scheme. Moreover, it is found that the choke flow of the $P 1$ scheme is about $5 \%$ higher than that of the $P 2$ scheme only at $50^{\prime} 000 \mathrm{rpm} \sim 6^{\prime} 000$ $\mathrm{rpm}$. The surge margin of the $P 3$ scheme is about $2 \%$ higher than that of $P 2$ scheme. Moreover, it is $17 \%$ higher than that of the $P 2$ scheme at a limited speed. However, the choke margin of the $P 3$ scheme is also smaller than that of the $P 2$ scheme.

Figure 6 and Fig. 7 show that the stabilization effect of the intake recirculation system with narrow slot width is not obvious. For compressors with an inlet diameter of about $135 \mathrm{~mm}$, the slot width should reach $3 \mathrm{~mm}$ to broaden the compressor flow range 

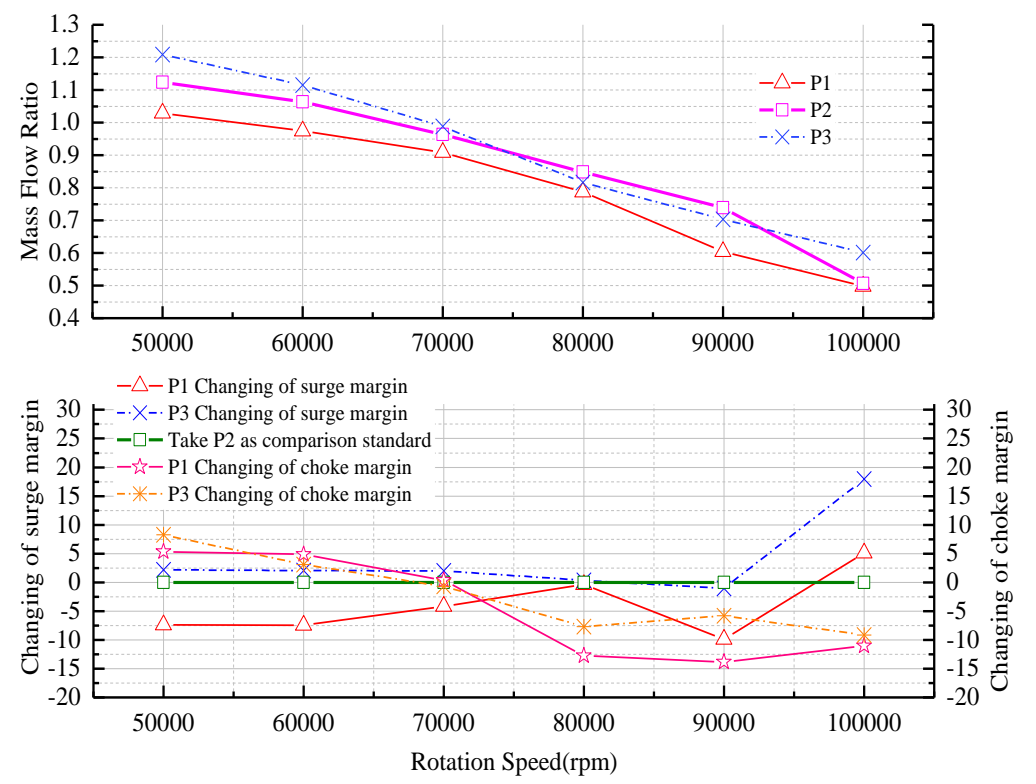

Fig. 7. Effect of the recirculation slot width on the compressor flow ratio, surge and choke.

Beyond this width, the flow range of the compressor does not change significantly, and the highefficiency area of the compressor is small. It is found that the width of the circulation system slot is not as wide as possible.

\subsection{The influence of the compressor recirculation slot position}

Figures 8 and 9 show the effect of the recirculation slot position on the compressor performance. The recirculation slot of $P 2, P 4$ and $P 5$ schemes is a straight slot structure and the slot widths are $3 \mathrm{~mm}$. Moreover, the positions of the recirculation slots are $L_{1}, L_{2}$ and $L_{3}$, respectively. The $L_{1}$ position is closer to the splitter blade of the impeller and the $L_{3}$ position is closer to the impeller inlet.

Figure 9 shows that the surge margin of the $P 5$ scheme is about $3 \%$ higher than that of the $P 2$ scheme, and the choke margin is about $7 \%$ higher than that of the $P 2$ scheme at low flow, and about 5\% lower than that of the $P 2$ scheme at high flow. When the speed is less than $80,000 \mathrm{rpm}$, the surge margin of the $P 4$ scheme is about $10 \%$ lower than that of the $P 2$ scheme. When the speed is $10,000 \mathrm{rpm}$, the surge margin of the $P 4$ scheme is about $20 \%$ higher than that of the $P 2$ scheme. Except at $7000 \mathrm{rpm}$, the choke margin of the $P 4$ scheme is lower than that of the $P 2$ scheme. It is observed that the closer the position of the circulation slot to the impeller splitter blade, the greater its influence on the surge point of the compressor, and the smaller the high-efficiency area with an efficiency of $80 \%$. This is due to the interference caused by the bypass gas entering the main airflow. Meanwhile, the gas flow through both the main and the splitter blades of the impeller generates shock waves. The disturbance caused by the bypass airflow through the recirculation slot and the shock wave generated by the splitter blade are superimposed on each other. Therefore, the closer the recirculation slot to the splitter blades, the greater the interference of the recirculation flow with the main airflow. Figure 9 shows that the mass flow ratio of the $P 5$ scheme is the largest and that of the $P 4$ scheme is the smallest. This indicates that the closer the recirculation slot to the compressor inlet, the wider the compressor flow range, and the closer it is to the splitter blade, the narrower the compressor flow range. Compared with the $P 2$ scheme, when the circulation slot center is located at other positions, the performance curve is close to the large flow direction in the low-speed region and close to the small flow direction in the high-speed region.

In summary, in order to obtain a relatively large surge margin, the location of the recirculation slot should be in the middle area of the wind guide wheel and far away from the shunt blades.

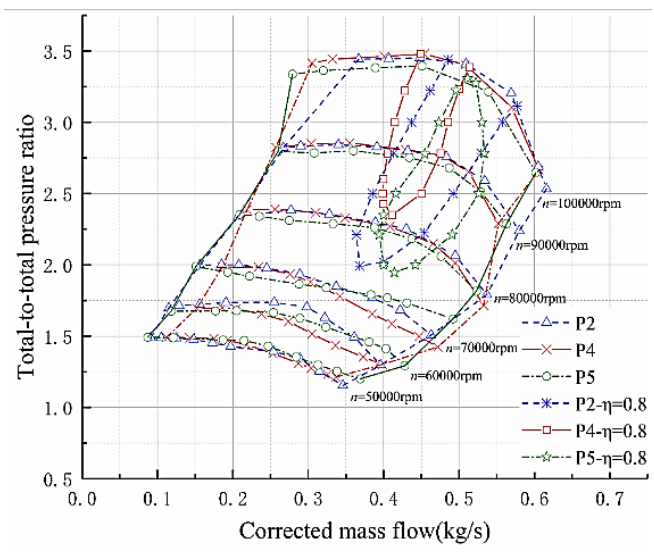

Fig. 8. Effect of the recirculation slot position on the compressor performance. 

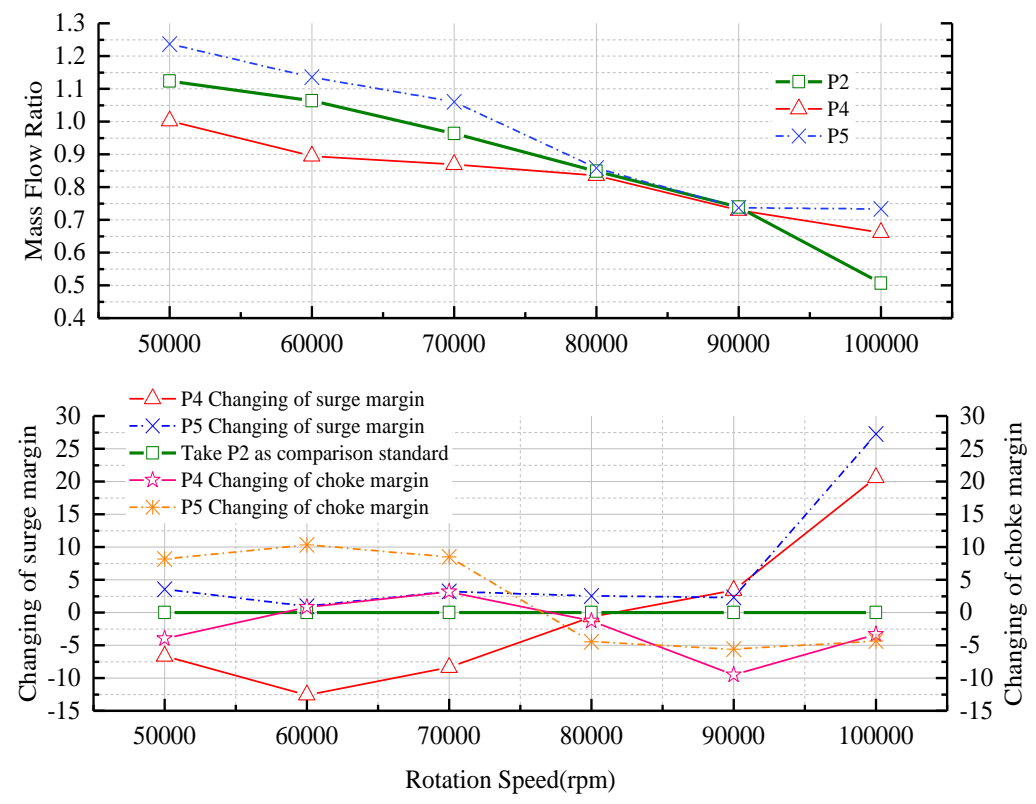

Fig. 9. Effect of the recirculation slot position on the compressor flow ratio, surge and choke.

\subsection{The influence of the compressor recirculation slot structure}

Figures 10 and 11 show the effect of the recirculation slot structure on the compressor performance. The recirculation slot of the $P 2, P 7$ and $P 8$ schemes are all at the $L_{2}$ position with a width of $3 \mathrm{~mm}$. Moreover, they are a straight slot structure, $24^{\circ}$ inclined slot structure and straight slot with intake collar structure, respectively. The $P 6$ scheme is a non-recirculation slot structure.

It is observed that the mass flow ratio of the nonrecirculation slot structure $(P 6)$ is about $5 \%$ 10\% larger than that of the straight slot structure $(P 2)$ in the low-speed region. However, in the high-speed region, the compressor enters the surge too early, and the choke margin of the P6 scheme is about $12 \%$ smaller than that of the $P 2$ scheme, which decreases its flow range. Moreover, the high-efficiency area becomes narrower and the constant speed line becomes steeper. The compressor with an inclined slot intake structure $(P 7)$ enters into the surge prior to the compressor with a straight slot intake structure $(P 2)$ at the speed of $50000 \mathrm{rpm} \sim 60000 \mathrm{rpm}$. Moreover, the surge margin is about $7 \%$ larger and the high-efficiency area is narrower in the high-speed region, while the efficiency circle tends to move towards the direction of the large flow.

This is because the inclined slot structure makes the bypass recirculation flow more smoothly into the main flow area than the straight slot structure, thereby increasing the bypass flow. However, in this condition the interference to the main flow of the impeller increases. The position of the chokepoint of the straight slot with the intake collar structure $(P 8)$ is similar to that of the straight slot structure $(P 2)$. However, its surge margin is about 20\% 25\% smaller than $P 2$ scheme, which minimizes the mass flow. Moreover, the area of the high-efficiency area is smaller and the pressure ratio of the constant speed line drops faster at a higher speed. This is due to the choke effect of the retaining collar. The higher the impeller speed, the higher the mass flow rate, the faster the flow velocity in front of the impeller, and the more obvious the choke effect.

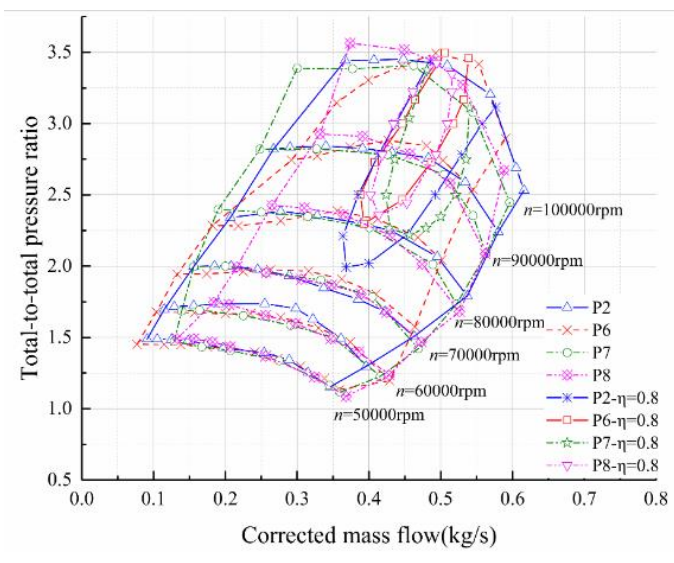

Fig. 10. Effect of the recirculation slot structure on the compressor performance.

Therefore, adopting the recirculation system of the compressor can extend the flow range of the compressor. The circulation slot with a nonretaining collar structure has a wider flow range than that with an intake collar structure, and the effect of the inclined slot structure is better than that of the straight slot structure. In previous research work, we found that the noise of the compressor with the intake collar structure is reduced. Therefore, compressors 

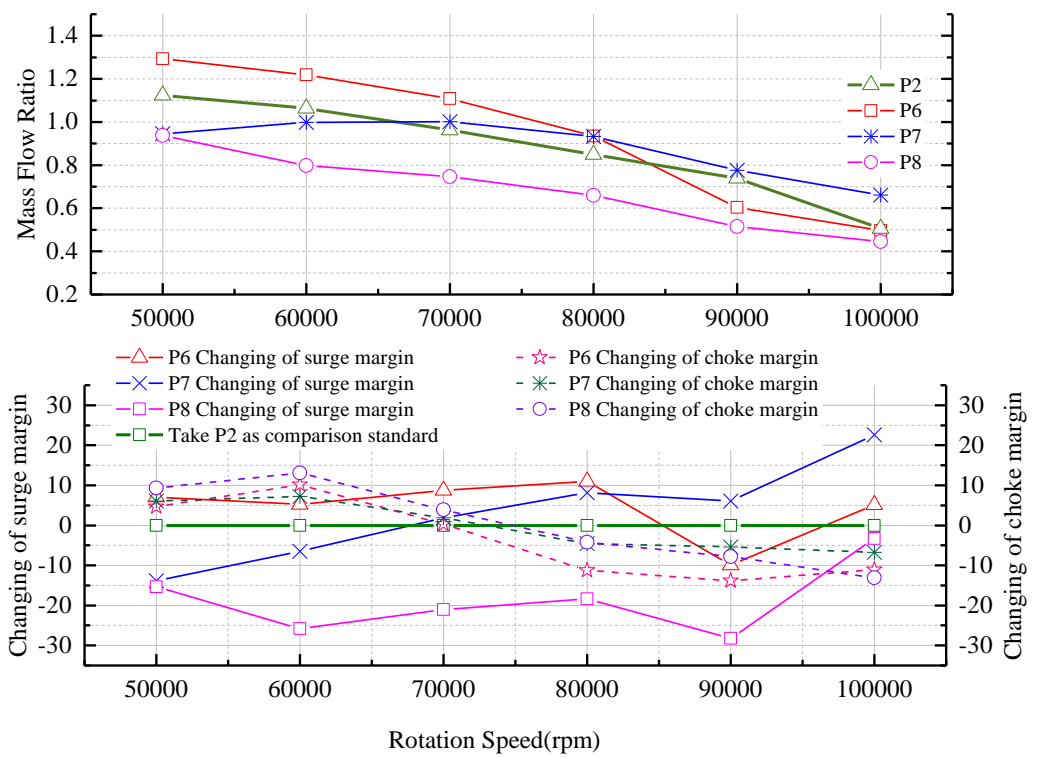

Fig. 11. Effect of the recirculation slot structure on the compressor flow ratio, surge and choke.

with an intake collar structure are used on engines that have strict requirements for noise, and compressors without intake collar structure should be selected in order to pursue higher performance within the scope of noise conditions.

Comprehensive analysis of the slot width, position and structure of the recirculation system, it is found that the recirculation system without intake collar structure has good stabilization ability. Compared with the position of the recirculation system, the slot width has a greater impact on the performance of the compressor.

\section{CONClusions}

In the present study, the compressor characteristic curves of different width, position and structure of the recirculation slot are analyzed by experimental research methods. The following conclusions are drawn from the present study:

(1) The bypass flow rate increases as the circulation slot width increases. When the recirculation system slot width is $2 \mathrm{~mm}$, the surge and choke margins are about $12 \%$ lower than those of the compressor with a slot width of $3 \mathrm{~mm}$. When the width of the circulation slot continues to increases, the flow range of the compressor does not continue to expand. Moreover, the area of the high-efficiency circle of the compressor decreases as the circulation slot width increases. It is observed that the width of the circulation system slot should reach $3 \mathrm{~mm}$, and not as wide as possible.

(2) The surge margin of the P5 scheme is about 3\% higher than that of the $P 2$ scheme, and the choke margin is about $7 \%$ higher than that of the $P 2$ scheme at low flow, and about $5 \%$ lower than that of the $P 2$ scheme at high flow. The overall surge margin and choke margin of the $P 4$ scheme are lower than those of the $P 2$ scheme. Therefore, the closer the recirculation slot position to the compressor inlet, the wider the compressor flow range and the larger the area of the high-efficiency circle. In order to obtain a relatively large surge margin, the recirculation slot should be located in the middle area of the wind guide wheel and far away from the shunt blades.

(3) Compared with the compressor with the recirculation structure, the compressor without the recirculation structure enters the surge prematurely in the high-speed range, the flow range is smaller, the high-efficiency range is narrow, and the speed line is steeper. Moreover, the compressor without an intake collar structure should be within the allowable range of noise conditions. Compared with the compressor with a straight slot intake structure, the compressor with an inclined slot intake structure has a greater surge margin in the highspeed region and a smaller high-efficiency circle. Furthermore, the efficiency circle moves towards higher mass flow conditions.

The obtained results of the present study can be utilized in the design and production process of the turbocharger. Therefore, a more suitable recirculation system structure can be obtained to reach a wider stable working range.

\section{ACKNOWLEDGEMENTS}

The authors appreciate the Liaoning Provincial Natural Science Foundation of China under Grant 2019-MS-160 and Xingliao Yingcai Program of Liaoning Province under Grant XLYC1807150. 


\section{REFERENCES}

Fisher, F. (1989). Application of Map Width Enhancement Devices to Turbocharger Compressor Stages. SAE 880794

Harley, P., S. Spence, D. Filsinger, M. Dietrich and J. Early (2015). Meanline Modeling of Inlet Recirculation in Automotive Turbocharger Centrifugal Compressors. Journal of Tuobomachinery 137(1), 011007.

Harley, P., S. Spence, J. Early, D. Filsinger and M. Dietrich (2014, May). Inlet recirculation in automotive turbocharger centrifugal compressors. 11th International Conference on Turbochargers and Turbocharging 13-14, 89100.

He, X. and X. Zheng (2019). Roles and mechanisms of casing treatment on different scales of flow instability in high pressure ratio centrifugal compressors. Aerospace Science and Technology 84, 734-746.

Mao, X., B. Liu and H. Zhao (2018). Numerical analysis of the circumferential grooves casing treatment in a counter-rotating axial flow compressor. Applied Thermal Engineering 130(5), 9-39.

Mirzabozorg, M. A. S., M. Bazazzadeh and M. Hamzezade (2017). Numerical study on the effect of single shallow circumferential groove casing treatment on the flow field and the stability of a transonic compressor. Journal of Applied Fluid Mechanics 10(1), 257-265.

Moffat, R. J. (1988). Describing the Uncertainties in Experimental Results. Experimental Thermal and Fluid Science (1), 3-17.

Mojaddam, M., A. Hajilouy-Benisi, M. R. Movahhedy (2014). Optimal design of the volute for a turbocharger radial flow compressor. Proceedings of ASME Turbo Expo 2014: Turbine Technical Conference and Exposition, Düsseldorf, Germany. GT2014

Nan, X., N. Ma, F. Lin, H. Takehiro and W. Toshinori (2018). A new approach of casing treatment design for high speed compressors running at partial speeds with low speed large scale test. Aerospace Science and Technology 72, 104-113.

Ramzi, M. and G. AbdErrahmane (2013). Passive control via slotted blading in a compressor cascade at stall condition. Journal of Applied Fluid Mechanics 6(4), 571-580.

Tamaki, H. (2010, June). Effect of Recirculation Device on Performance of High Pressure Ratio Centrifugal Compressor. Proceeding of ASME Turbo Expo 2010: Power for Land, Sea and Air, Glasgoe, UK, GT2010-22570.
Tamaki, H. (2012). Effect of Recirculation Device with Counter Swirl Vane on Performance of High Pressure Ratio Centrifugal Compressor. Journal of Turbomachinery.134 (5):051036.

Tamaki, H., M. Unno, R. Tanaka, S. Yamaguchi and Y. Ishizu (2015, June). Enhancement of Centrifugal Compressor Operating Range by Control of Inlet Recirculation with Inlet Fins. ASME Turbo Expo 2015: Turbine Technical Conference and Exposition, Montreal, Canada, GT2015-42154.

Wang, W., J. Lu, X. Luo and W. Chu (2019, December). Coupling method of stability enhancement based on casing treatments in an axial compressor. Aerospace Science and Technology 95, 105449.

Xiao, J., W. Xu, C. Gu and X. Shu (2009). SelfRecirculating Casing Treatment for a Radial Compressor. Chinese Journal of Mechanical Engineering 22(4), 567-573.

Yang, C., S. Chen, D. Li, C. Yang and Y. Wang (2010). Inlet Recirculation Influence to the Flow Structure of Centrifugal Impeller. Chinese Journal of Mechanical Engineering 5, 115122.

Yang, C., Y. Wang, D. Lao, D. Tong, L. Wei and Y. Liu (2016aa). Investigation on Inlet Recirculation Characteristics of Double Suction Centrifugal Compressor with Unsymmetrical Inlet. Journal of Thermal Science 25(4), 312324.

Yang, M., R. Martines-botas, K. Deng, Y. Zhang and $X$. Zheng (2016b). Unsteady influence of self recirculation casing treatment (srct) on high pressure ratio centrifugal compressor. International Journal of Heat and Fluid Flow $58,19-29$

Yang, M., X. Zheng, Y. Zhang, T. Bamba, H. Tamaki, J. Huenteler and Z. Li (2013). Stability Improvement of High-Pressure-Ratio Turbocharger Centrifugal Compressor by Asymmetric Flow Control-Part I: NonAxisymmetric Flow in Centrifugal Compressor. Journal of Turbomachinery 135(2), 210061210069.

Zheng, X., Y. Zhang, M. Yang, T. Bamba and H. Tamaki (2013, March). Stability Improvement of High-Pressure-Ratio Turbocharger Centrifugal Compressor by Asymmetrical Flow Control-Part II: Nonaxisymmetrical SelfRecirculation Casing Treatment. Journal of Tuobomachinery 135, 021007.

Zhu, D. (1992). Turbine and turbocharger. Beijing: Industry Press. 126-132. 